\title{
GOVERNANÇA URBANA NEOLIBERAL E AS OPERAÇÕES URBANAS CONSORCIADAS EM FLORIANÓPOLIS Ideologia e ademocracia engavetando o planejamento
}

\section{NEOLIBERAL URBAN GOVERNANCE AND THE URBAN OPERATIONS IN FLORIANÓPOLIS Ideology and ademocracy having plans lie on the shelf}

\author{
A. Renan Santos Gomez \& B. Tomás Antonio Moreira \\ IAU-USP, Instituto de Arquitetura e Urbanismo; Universidade de São Paulo, Brasil \\ renan.s.gomez@gmail.com \\ tomas_moreira@sc.usp.br
}

\begin{abstract}
RESUMO
Este trabalho aborda o histórico das Operações Urbanas Consorciadas (OUCs) no processo de aprovação do novo Plano Diretor de Florianópolis-SC (2014), na perspectiva da governança urbana, buscando constituir uma análise desse desenho de parceria público-privada como conformador de uma disputa de agentes urbanos, e como a supressão da participação popular dentro das discussões nas diferentes fases do anteprojeto de Lei do Plano Diretor, constituiu instrumentos urbanísticos inviáveis. O trabalho faz uma revisão bibliográfica e levantamento documental sobre o processo de proposição das OUCs no Plano Diretor até a sua aprovação em 2014, analisando os resultados e encaminhamentos relativos ao desenvolvimento urbano florianopolitano, juntamente a esses instrumentos. As propostas de OUC analisadas denotam uma preocupação momentânea de ímpeto mercadológico das Operações de Florianópolis, bem como uma ideia de planejamento descartável, que não vislumbra solidamente um futuro nem um projeto de cidade.
\end{abstract}

Palavras-chave: operação urbana consorciada, planejamento urbano, Plano Diretor, participação Linha de Investigação: 1: Cidade e projeto

Tópico: Planejamento, políticas e governança

\section{ABSTRACT}

This paper addresses the history of the Urban Operations during the approval process of the new Master Plan of Florianópolis-SC (2014) from the perspective of urban governance, seeking to constitute an analysis of this public-private partnership model as a shaper of a dispute between urban agents, and how the suppression of popular participation within the discussions in the different phases of the draft Master Plan Law constituted unviable urban instruments. The work makes a bibliographic review and documentary survey on the OUCs 


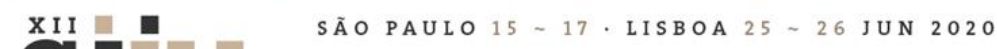

proposal's process in the Master Plan until its approval in 2014, analyzing the results and referrals related to Florianopolitan urban development, together with these instruments. The OUC proposals analyzed denote a momentary concern of market momentum for the Florianópolis' Operations, as well as a disposable planning idea, which does not solidly envision a future or a city project.

Keywords: Urban Operation, urban planning, Master Plan, Participation

Research line: 1: City and project

Topic: planning, policies and governance

\section{Introdução}

Sob um novo dispositivo global e totalizante, as políticas de desenvolvimento urbano brasileiras e as próprias gestões estaduais e municipais encontraram novas formas de funcionamento, fundamentalmente modificando os processos de produção do espaço urbano. O Brasil, carregando seus problemas históricos de formação urbana, passa hoje por movimentos que instrumentalizam a população, imprimindo novas formas de disputa de interesses de cada ator social nos processos decisórios sobre o destino das cidades.

Esses instrumentos, entretanto, encontram suas limitações. Um deles, que ganhou destaque nos últimos anos, é a Operação Urbana Consorciada (OUC). A associação do Estado brasileiro às novas formas de gestão e empresariamento do território, porém, incentivam a repaginação das antigas práticas históricas que capturam o controle do desenvolvimento urbano, inclusive no caso da elaboração e execução de OUCs. Seus processos participativos são comprometidos e desequilibram as disputas de interesses ocorridas em seus processos decisórios.

Este trabalho é um ensaio que aborda o histórico das Operações Urbanas Consorciadas no processo de aprovação do novo Plano Diretor (PD) do Município de Florianópolis-SC (LC no 482/2014) na perspectiva da governança urbana, buscando constituir uma análise desse desenho de parceria público privada como conformador de uma disputa de agentes urbanos, e como a supressão da participação popular dentro das discussões dos diferentes anteprojetos de Lei do Plano Diretor publicados, bem como no PD aprovado, constituiu instrumentos urbanísticos inviáveis para devida execução, segundo o Estatuto da Cidade (2001).

O Plano Diretor de 2014 de Florianópolis foi construído dentro de um longo e polêmico processo, a ponto de ser judicializado após a sua aprovação na Câmara de Vereadores (Gonçalves, 2017; Siqueira, 2019a). Dentro dele, as propostas de OUCs passaram por diferentes versões, com pouca ou nenhuma discussão oficial nas esferas participativas promovidas pelo município (Ávila, 2013a; 2013b). Hoje, sua eventual implementação é vista com grande ceticismo por parte da iniciativa privada e dos gestores públicos.

Existiria, dentro desse contexto, uma lógica vigente interpenetrada na questão do planejamento e desenvolvimento urbano de Florianópolis e refletida na configuração das OUCs e nos modelos de disputas democráticas entre os agentes urbanos em sua construção? Que lógica é essa? Este artigo foi construído como parte de um trabalho de mestrado em andamento financiado pela FAPESP - Fundação de Amparo à Pesquisa do Estado de São Paulo, processo no2018/26018-7. É parte da prospecção de dados e análises momentâneas do histórico de proposições de um instrumento urbanístico tão popularizado como as Operações Urbanas Consorciadas, dentro da construção do novo Plano Diretor de Florianópolis. 


\section{SÃOPAULO15 $\quad 17 \cdot$ LISBOA $25 \sim 26$ JUN 2020}

\section{Neoliberalismo como Dispositivo e a Cidade Contemporânea}

O capitalismo, como sistema, é dependente de sua expansão para sobrevivência e decorre de uma normativa de altos e baixos, que se estabelecem em crises e retomadas baseadas em sua metamorfose constante, de forma a viabilizar, necessariamente, a superação dessas sucessivas crises (Harvey, 2005). 0 neoliberalismo, produto da exacerbação de algumas características em diversos níveis utilizadas para atingir constantemente certo grau de expansão do capital, guarda sua própria lógica e desenvolvimento histórico, sendo dado de transformação do capitalismo e das sociedades em torno do globo - é um sistema normativo, no sentido de ultrapassar as dimensões de simples ideologia ou de política econômica para tomar todas as dimensões da vida a partir da lógica do capital - não se configurando, dessa forma, como puramente o capitalismo contemporâneo em mais uma de suas formas, mas a própria razão deste (Dardot, 2016).

\subsection{A nova subjetivação e o Estado}

Por suas características englobantes, o dispositivo neoliberal é abrangente na conformação das lógicas de funcionamento de todos os aspectos da vida contemporânea. Abarca "dispositivos discursivos, institucionais, políticos, jurídicos e econômicos que formam uma rede complexa e movediça" (Dardot, 2016: 384). O Estado, no processo de crescimento e enraizamento desta subjetivação, de maneira geral, possui um papel determinante, principalmente partindo dos centros de poder mundiais. A lógica concorrencial e o modelo empresarial, por meio destes, se estabelecem na economia, na sociedade e inclusive dentro dos próprios Estados (Dardot, 2016; Misoczky, 2017).

O Estado-empresa neoliberalizado incorporou de forma gradativa a lógica concorrencial econômica privada, e foi se alterando internamente com uma dinâmica de privatizações generalizadas, ao mesmo tempo que, externamente, reformula seus instrumentos de poder (Idem, Ibidem). A ideia de Estado gerencial eficaz, a desvalorização de lógicas socialmente solidárias e da ação pública subvertem os fundamentos democráticos a partir da aceitação e incorporação de um modo de gestão genérico, agora validado para todos os domínios. A "melhoria" do desempenho da ação pública, aqui, é objetivada a partir de medições comparativas a de outros atores privados, apesar de carregarem objetivos fundamentalmente distintos, deslocando o Estado para o mesmo plano dessas entidades (Dardot, 2016).

Apesar do reconhecimento generalizado de que o planejamento urbano construído de forma democrática é pedra fundamental para a formação urbana, esta padece sob uma racionalidade ademocrática de motivação ideológica por parte das gestões municipais. Soma-se a isso a transferência do controle e o "fazer cidade" das mãos do Estado para os setores privados, aprofundando as barreiras para implementação real daquele tipo de conduta. É dentro dessa lógica que são criados e implementados instrumentos urbanos como as Operações Urbanas Consorciadas no Brasil.

\section{Planejamento urbano democrático e as Operações Urbanas Consorciadas em Florianópolis}

As OUCs no Brasil, apesar de difundidas nas Leis de Planos Diretores de diversas cidades, ainda são relativamente pouco executadas, e as experiências ainda estão concentradas em grandes centros metropolitanos. Para Florianópolis, é um instrumento inédito, tendo pouca clareza dos seus potenciais positivos e destrutivos por parte das gestões. Como elas chegaram no desenho que possuem hoje? As elites locais têm seu mercado de terras repetidamente beneficiado no tempo, através de grandes obras que, além de concentrar equipamentos, principal e predominantemente promovem conexões viárias (Sugai, 2002; 


\section{SÃOPAULO15 $\quad 17 \cdot$ LISBOA $25 \sim 26$ JUN 2020}

Kronenberger, 2019). Associada a essa utilização histórica dos investimentos na cidade em favor de alguns grupos hegemônicos, devemos nos atentar a seus possíveis impactos sociais, ambientais e infraestruturais.

Essas estruturações e reestruturações urbanas encabeçadas por reconfigurações e ampliações de vias automobilísticas se deram, via de regra, através de modelos de planejamento substancialmente de cima para baixo, que permitiram livremente a promoção, por parte do Estado, da reprodução do capital em favor de frações predominantemente locais das elites capitalistas (Sugai, 2002; Siqueira, 2019a).

Devemos ter em conta o processo de disputa dentro da construção do novo Plano Diretor: qual é o histórico propositivo dessas OUCs - e considerar quem são os atores participantes dessas propostas, e quais os interesses relativos a elas, no tempo. Atentando-se às diversas fases de desenvolvimento do Plano Diretor, é possível construir um mapa temporal das diferentes propostas dessas operações, avaliando, dentro do vai-evem do Plano Diretor (Gonçalves, 2017), que projetos de cidade essas grandes propostas de reconfiguração urbana defendem, e que equipamentos, infraestruturas e programas sociais elas propõem dentro dos tecidos urbanos florianopolitanos - e onde, nesses tecidos.

Isso deve permitir, também, que façamos uma breve análise do desenho institucional dos circuitos de decisão reservados especificamente para o assunto das OUCs, que interesse teve e que espaço conseguiu a sociedade civil organizada nessas instâncias de decisão. Observados esses aspectos, espera-se também poder examinar as interferências dos diferentes agentes no desenho atual dessas propostas, tanto durante seu desenvolvimento nos últimos anos, como em seu desenho final.

\subsection{Operações Urbanas Consorciadas}

A Operação Urbana Consorciada (OUC) é um instrumento urbanístico proposto pelo Estatuto da Cidade e defendido, em seus princípios, como uma possibilidade de uso de investimento privado em melhorias urbanas. Através dela, seria possível promover um combate às dinâmicas socioespaciais excludentes impulsionadas pelo mercado imobiliário. A valorização da terra urbana seria direcionada pela apropriação da legislação urbana dentro de um perímetro selecionado, numa iniciativa em prol de gerar mudança da forma tradicional brasileira de se produzir cidade (Maricato, 2002; Siqueira, 2017).

Para que se efetive, uma OUC precisa ter um recorte espacial claro, onde novas normas edilícias, de usos, entre outros, se associam à compra e venda de potenciais adicionais de construção, a contrapartidas financeiras ou obras diretas para implementar um programa de melhorias urbanas dentro do referido recorte. A utilização dos recursos fica restrita ao perímetro da Operação, estando sob controle e acompanhamento da sociedade civil. Trata-se de um instrumento de alta complexidade e que demanda grande capacidade administrativa e de planejamento, precisando ser amparado por uma relação impulsionadora dele mesmo com o microzoneamento e outros instrumentos: "as OUCs necessitam de sistemas de planejamento urbano fortalecidos e de instituições locais comprometidas com um claro modelo de desenvolvimento para a cidade" (Siqueira, 2019a).

Vemos, porém, muitas experiências esquivas destas prerrogativas no Brasil. Remoções em massa, configurações autoritárias das formas de planejamento e redirecionamento dos fundos adquiridos em detrimento de partes importantes do programa em temos sociais são fenômenos que podem ser observados, por exemplo, em São Paulo e Rio de Janeiro (Fix, 2009; Maricato, 2002; Siqueira, 2017). Projetos de habitação social sistematicamente perderam espaço para obras de vias de tráfego rápido, túneis e ressarcimento das comunidades atingidas pelos processos de expulsão, essas que, via de regra, são populações pobres e que, por vezes, têm sua presença substituída por parte do programa implementado, 


\section{XII \\ Seminário Internacional de Seminario Internacional de Investigação em Urbanismo Investigación en Urbanismo}

uma série de indicativos de desdemocratização do desenvolvimento das OUCs que são percebidos nessas ocorrências. Uma negação da cidade democrática ou uma ademocracia: na ideologia e subjetivação hegemônica neoliberal que envolve a produção das cidades, o cidadão não encontra direito à cidade (Harvey, 2008): nem espaço de participação, nem de gozo pleno das novas estruturas urbanas propostas e criadas.

\subsection{O Caso de Florianópolis: As OUCs no tempo dentro da construção do Plano}

A montagem das OUCs e como elas são abordadas no tempo serão observadas, reunindo, na medida do possível, as informações sobre o processo de construção desses instrumentos dentro das discussões do Plano Diretor. Deste, ao todo, foram elencadas quatro fases de construção até 2014. Existem mais três minutas, elaboradas posteriormente no processo de revisão constituído pelo Instituto de Planejamento Urbano de Florianópolis (IPUF), mas com seu engavetamento, a partir de decisão judicial, não trataremos destas últimas neste trabalho.

\subsubsection{Anteprojeto de Lei Plano Diretor Desenvolvimento Sustentável de Florianópolis - 16/03/2010}

A discussão será disposta em ordem cronológica, com o momento em que nasce a ideia de implantar OUCs em Florianópolis. Mesmo não sendo mencionados no processo participativo realizado desde 2006, um conjunto de 11 perímetros (Ávila, 2013a), indicados na Fig. 1, é apresentado como forma de instrumentalizar novas reconfigurações urbanas.

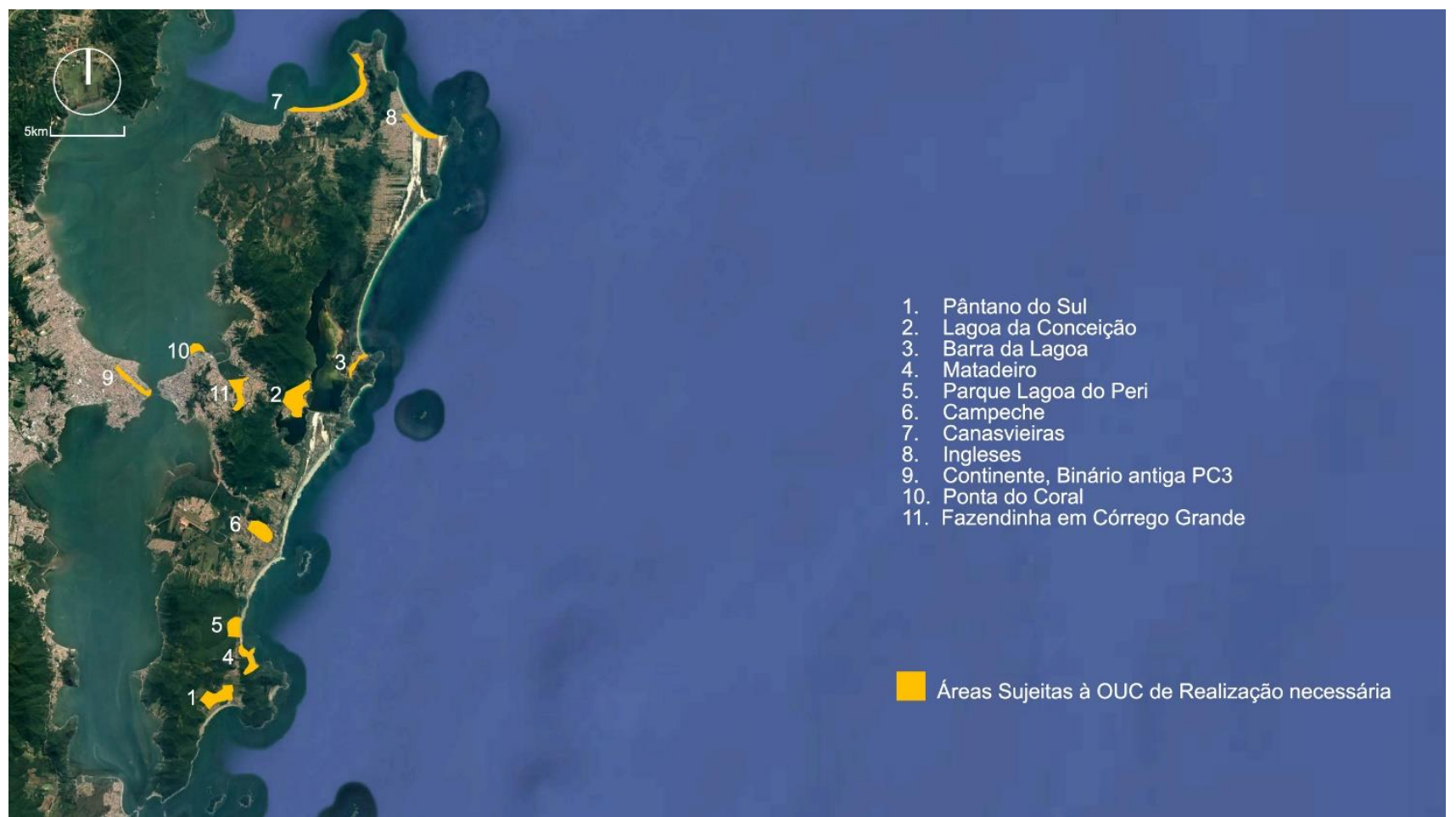

Fig 1 Áreas Sujeitas a OUC de Realização Necessária - Anteprojeto de Lei Plano Diretor Desenvolvimento Sustentável de Florianópolis, de 16/03/2010. Elaboração própria, com base em dados da CEPA/IPUF e Ávila (2013a). 


\section{SÃOPAULO $15 \sim 17 \cdot$ LISBOA $25 \sim 26$ JUN 2020

O fato dos investimentos arrecadados se limitarem ao perímetro de determinada OUC predispõe que, já nos planos diretores, as dinâmicas de mercado sejam elemento primordial da delimitação das áreas a sofrerem intervenção (Maricato, Siqueira, 2017). Considerando a necessidade de valorização suficiente que existe para atrair grandes capitais, as áreas escolhidas, via de regra, são aquelas já com alto potencial de valorização e que já possuem um entorno privilegiado. De certa forma, este fato é um contraditório presente na ideia de melhoramentos urbanos que promove as OUCs, mas que a insere no contexto dos instrumentos urbanísticos como uma alternativa ao espraiamento e ferramenta de repaginação de centralidades, que podem contribuir com infraestruturas urbanas mais eficientes.

Não é, consistentemente, o caso observado em Florianópolis, já desde o primeiro Anteprojeto de Plano Diretor publicado. Dispersos pelo território florianopolitano, de passado histórico de formação polinucleado e disperso, os perímetros propostos seguiram lógicas diversas, e atingindo desde territórios centrais até áreas com pouquíssima consolidação urbana. Considerando a legislação urbanística que acompanha os mapas de perímetros de OUCs, e as características territoriais e históricas de cada lugar, as OUCs de 2010 parecem ter sido inseridas muito mais como demarcação de interesse mercadológico do que de real intenção de implantação de "transformações urbanísticas estruturais, melhorias sociais e a valorização ambiental" (Estatuto da Cidade, 2001: 30), como propõe a lei federal.

As OUCs, após um primeiro momento entre 2006 e 2008, de ampla participação para a elaboração de diretrizes para a elaboração do PD e posterior desmonte das instâncias participativas existentes (Sampaio, 2016), foram introduzidas nas discussões, já como propostas. Deram-se dentro do trabalho majoritariamente conduzido em parceria com o IPUF, principal órgão de planejamento urbano municipal, pelo Centro de Estudos e Planificação do Meio Ambiente (Fundação CEPA), em um momento em que a prefeitura dissolveu as instâncias participativas existentes. Trata-se de uma empresa argentina contratada pela gestão municipal que, segundo Ávila (2013a, 2013b), falhou em unir as diretrizes populares e técnicas realizadas nos anos anteriores para o Plano Diretor encomendado, priorizando interesses privados no produto entregue. Por parte da população, segundo a autora, não houve inclusão participativa no caso das OUCs.

Diversos perímetros de Operações, dentro deste trabalho, encontram-se em regiões sem urbanidade constituída, colocando-se, de maneira geral, como propostas de expansão urbana ou de avanço sobre áreas de proteção ambiental, como o caso do Porto da Barra (OUC 3) e Pântano do Sul (OUC 1), e de áreas de valor histórico, cultural e ambiental, como a Ponta do Coral (OUC 10). Ávila (2013a) identificou também tentativas de uso do instrumento como ferramenta de privatização urbana de terrenos da União, como é o caso do Campo de Aviação do Campeche (OUC 6), e para se sobrepor a zonas de baixa densidade, numa perspectiva de sobrepujar reivindicações históricas comunitárias de limitação de gabarito, tais como no caso da Lagoa da Conceição (OUC 2).

A lógica de beneficiamento de grandes grupos comparece também no texto do anteprojeto de lei. Nele, são elencados objetivos específicos para cada OUC, mesmo sem lei específica. Apesar de garantir amplo espaço para a indústria hoteleira, comércio e habitações multifamiliares, a habitação social como requisito básico só aparece uma vez, curiosamente para a única OUC fora da ilha de Santa Catarina (Florianópolis, 2010). A falta de menção à necessidade de Habitação de Interesse Social na porção insular reforça a continuidade das dinâmicas de segregação socioespacial histórica da capital (Sugai, 2002; Kronenberger, 2019), e a preponderância da lógica de abertura e indexação de novos mercados para o instrumento urbanístico. 


\section{SÃO PAULO15 17 LISBOA $25 \sim 26$ JUN 2020

É possível observar, porém, alguma preocupação em promover "cidade pública", ao mesmo tempo em que se promove o beneficiamento de entidades privadas através do texto do anteprojeto de lei. Das garantias mais recorrentes de cunho potencialmente comunitário, temos "superfícies destinadas a áreas verdes, esportivas de lazer de uso comunitário e ou privado"," Áreas de Interesse Ambiental e Paisagístico (APC-2), e Área Comunitária Institucional, possuindo algum peso frente às garantias beneficiadoras da indústria hoteleira e imobiliária.

As OUCs concentradas na parte norte da llha, onde se encontram os principais e históricos eixos de valorização, concentraram também investimentos para valorização da praia como objeto turístico e obtenção de dispositivos de beneficiamento direto a entidades privadas. Previram geração de grandes impactos ambientais, caso os Estudos de Impacto Ambiental e ações compensatórias adequadas não fossem devidamente realizados. Do ponto de vista econômico, porém, estas propostas se colocaram como possibilidade de impulsionamento das atividades econômicas da população e ampliação das oportunidades locais, bem como um retorno excelente de renda de monopólio aos proprietários locais de terrenos à beiramar.

De qualquer maneira, as propostas de OUC elencadas na versão do PD de 2010 não parecem ter o instrumento realmente compreendido dentro do ideário disposto no Estatuto da Cidade, haja vista que suas propostas já aparecem sem se atentar às demandas gerais do instrumento para vislumbrar uma efetivação dos casos observados no Anteprojeto de 2010. Priorizam ganhos mercadológicos em detrimento de ganhos sociais, com uma visão de apropriação de superfícies limitadas por condicionantes naturais, legais ou sociais para impulsionamento e exploração do espaço urbano com viés predominantemente imobiliário e turístico.

Este modelo de OUC de 2010, porém, não foi promovido sozinho por entidades privadas. A despeito do processo de esvaziamento do qual o IPUF é vítima desde o fim da década de 1980 (Ávila, 2013b), um processo que deixou o órgão com um quadro limitado de funcionários para exercer todas as suas funções, as propostas de OUC tiveram participação direta do órgão e foi ao lado dele que as OUCs 4. Matadeiro, 5. Parque Lagoa do Peri, e 10. Ponta do Coral foram, ainda segundo Ávila (2013b), introduzidas pela prefeitura em adição às sugestões elaboradas pela consultoria da CEPA para a publicação deste Anteprojeto de Plano Diretor. Este esvaziamento, porém, é fator determinante dentro da lógica neoliberal de transferência de controles e encargos tipicamente da coisa pública ao privado: inicialmente limitada a um trabalho de consultoria, a Fundação CEPA tomou um papel de coordenação de projeto (Ávila, 2013b) que, pressupõe-se, deveria estar nas mãos do órgão municipal, dado que o planejamento municipal é de interesse público e incumbência dessa autarquia, além de que os técnicos locais possuem maior aproximação com a realidade local e com o Estatuto da Cidade (Idem, Ibidem).

\subsubsection{Anteprojeto do Plano Diretor de Florianópolis - 11/04/2012}

Após um trabalho de reformulação, ainda com acompanhamento por parte da Fundação CEPA até 2011, e com um Núcleo Gestor insatisfeito com a não contemplação das diretrizes distritais (Rocha, 2015), é publicado ainda na gestão do prefeito Dário Berger um novo Anteprojeto de Lei. Nele, as OUCs propostas sofrem consideráveis alterações em seus perímetros. Canasvieiras, Matadeiro e Parque Lagoa do Peri saíram das propostas para ceder lugar a uma nova, indicada para as regiões de cabeceira da ponte Hercílio Luz.

${ }^{1}$ Este detalhe, porém, chama atenção pela possibilidade de substituição completa do destino dessas áreas para usos não-públicos. Grifo nosso. 


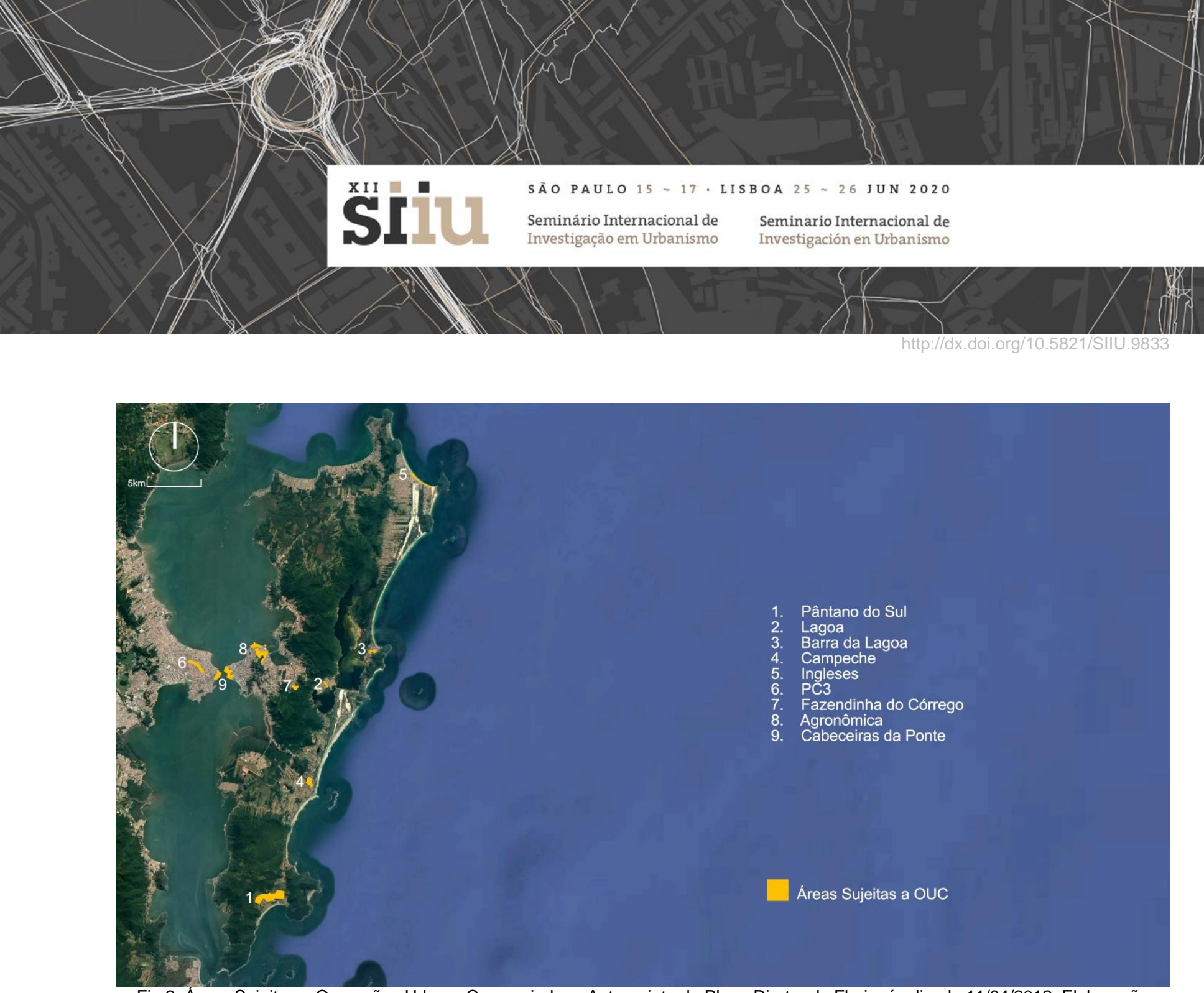

Fig 2. Areas Sujeitas a Operações Urbana Consorciadas - Anteprojeto do Plano Diretor de Florianópolis, de 11/04/2012. Elaboração própria, com base em dados do IPUF e Ávila (2013).

Os perímetros remanescentes sofrem redução generalizada em termos de área, motivo de estranhamento, em especial nos casos do Campeche, Lagoa da Conceição, Fazendinha e Barra da Lagoa. A timidez dos novos recortes de área condiz muito pouco com a ideia de implantação de grandes projetos urbanos do instrumento: intervenções pequenas têm potencial escasso de captura e movimentação de recursos suficientes para contemplar obras infraestruturais, dada a barreira de complexidade que uma OUC estabelece para o investimento privado nessas áreas. Além disso, a partir desta versão, o plano suprimiu as especificações relativas a cada área, aprofundando a nebulosidade com relação aos seus objetivos e ampliando a insegurança com relação ao instrumento.

Ávila (2013b) aponta, aqui, um descrédito já nesta fase com relação à aplicabilidade das Operações. Trata-se de um instrumento de alta complexidade e que demanda estudos cuidadosos para sua viabilização, algo que desde o princípio não ocorreu durante seu desenvolvimento. Em uma cidade com o porte de Florianópolis, e com um corpo técnico enxuto responsável pelo planejamento do município, parece mais cabível a introdução de outros instrumentos mais simples que atendam à demanda do mercado para a construção de novos equipamentos, mas que também sejam capazes de trazer contrapartidas para o Estado e o permitam direcionar os investimentos privados para o desenvolvimento florianopolitano.

\subsubsection{1aㅡ Minuta - Plano Diretor do Município de Florianópolis - 18/10/2013}

Com um Núcleo gestor desmobilizado desde 2012, e que seria novamente dissolvido ao final do processo (Rocha, 2015), a nova gestão envia sua versão à Câmara Municipal (Rocha, 2015). O PLC de 2013, então, estabelecia diversas mudanças em suas propostas de OUC, elencando Áreas Sujeitas a OUC também como AUEs: Áreas de Urbanização Especial em seu microzoneamento. Desfazendo-se de uma série de perímetros 


\section{XII \\ Seminário Internacional de Seminario Internacional de Investigação em Urbanismo Investigación en Urbanismo}

da última versão, surgem agora grandes glebas concentradas a norte da llha (Fig. 3), reconhecidamente um eixo de valorização e de interesse de expansão imobiliária, com este zoneamento inédito para o PD. Fora da região norte, apesar das AUEs se espalharem por vários distritos, apenas o Distrito de Ribeirão da Ilha tem uma OUC sobrepondo-se a este zoneamento, região em que era esperada a construção de um importante aeroporto. Este foi inaugurado ao fim de setembro de 2019, também configurando alterações significativas nas dinâmicas locais e novos eixos de valorização esperados para a região.

No texto do Projeto de Lei, as AUEs estão definidas como "grandes áreas urbanizáveis a partir de projeto amplo, que reserva setor predominante para preservação ambiental e adensa a área remanescente, criando novas centralidades caracterizadas pela mescla de funções e espaços humanizados" (Florianópolis, 2013: 18).

Um zoneamento genérico com um discurso de proteção ambiental e criação de novas centralidades, ao mesmo tempo em que serve como zona de amortecimento (Siqueira, 2019b), é contraditório por si só. Mas sua indefinição, aqui, pode indicar muito possivelmente uma reserva de área urbanizável a ser sobreposta pelo instrumento da OUC, potencialmente ampliando a liberdade de construir de acordo com a capacidade de mobilização desta, em detrimento de qualquer ideia de preservação ambiental ou de zona de amortecimento existente. Estas OUCs, porém, são uma barreira de complexidade, em um contexto como este, para processos normais de expansão urbana e, como já observado, têm pouca capacidade de atração e mobilização do mercado para sair do papel. O seu resultado anunciado se configuraria, na verdade, como de retração de investimentos privados para essas glebas, o que parcialmente se confirma com a sua estagnação até os dias atuais (Idem, ibidem).

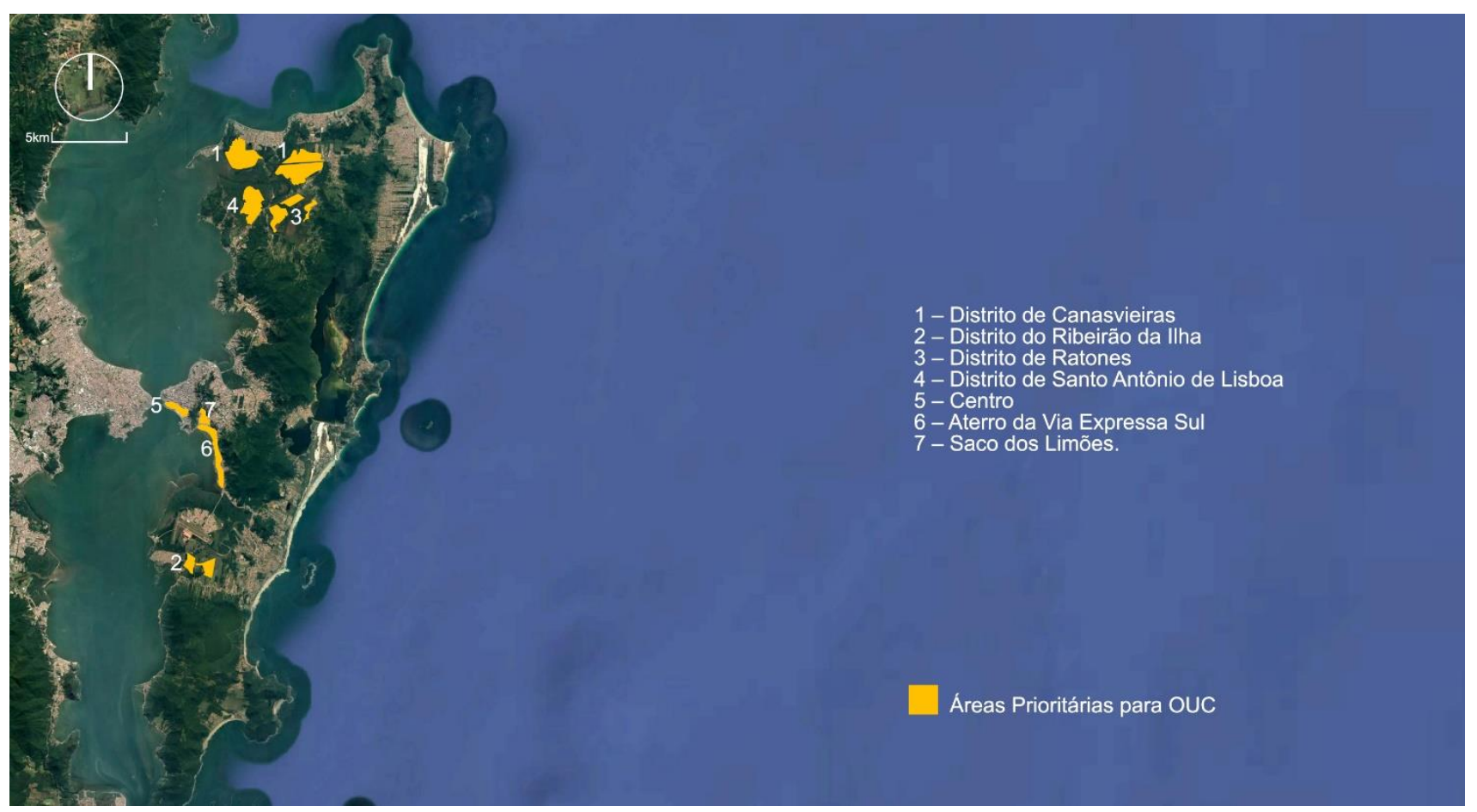

Fig 3 Áreas prioritárias de Operação Urbana Consorciada - Mensagem № 073/2013. Elaboração própria, com base em dados do IPUF, 2020. 


\section{XII \\ Seminário Internacional de Seminario Internacional de Investigação em Urbanismo Investigación en Urbanismo}

\subsubsection{Plano Diretor do Município de Florianópolis (PDMF) - 17/01/2014}

Dentro da Câmara dos Vereadores e já sofrendo pressões por parte do MPF, o Plano passa por duas sessões de votação, na qual são propostas 591 emendas. Elas são votadas em bloco, tendo 302 delas aprovadas (Sampaio, 2016). Obrigada judicialmente, a prefeitura promoveu novo processo participativo, compondo três novas minutas do Plano, mas que, com a decisão favorável ao PD aprovado, em 2017, feita pela desembargadora Marga Inge Tessler, do Tribunal Federal da 4 ${ }^{a}$ Região, foram descartadas. O PDMF de 2014, a partir daqui, passa a vigorar plenamente (Gonçalves, 2017).

Com relação às OUCs, o Plano aprovado segue ignorando uma série de questões relativas à aplicabilidade do instrumento e seus objetivos. A manutenção das propostas de OUCs nubladas e, por vezes, com aprofundamento de suas indefinições, é reflexo do descuido sistemático sustentado pelas diferentes mãos que compuseram o Plano pelos cinco anos anteriores. Independentemente de qualquer processo participativo que tenha sido feito, a casa legislativa retira a OUC de Santo Antônio de Lisboa e insere um novo perímetro às margens da BR-282 na área continental, mas fora do eixo da antiga PC3 (Fig. 4).

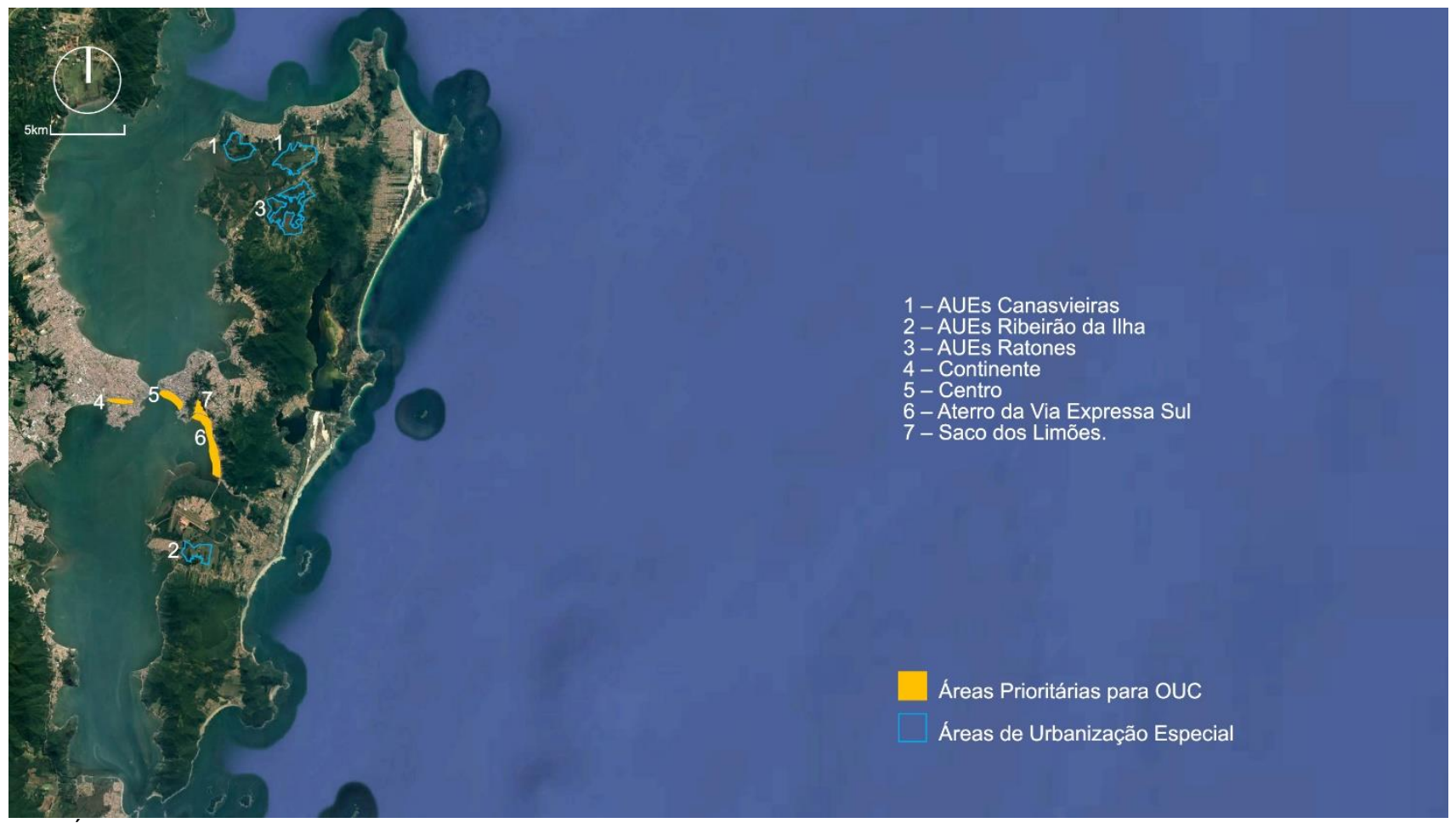

Fig 4 Áreas prioritárias de Operação Urbana Consorciada - LC no 482/2014, com demarcações das AUEs em regiões com OUC no texto da lei. Elaboração própria, com base em dados do IPUF.

Nesta troca abrupta promovida dentro da assembleia legislativa, surpreendentemente o caso da OUC Continente é um dos que mais possuiria capacidade de realização, dada a sua caracterização urbana e de seu entorno. O zoneamento aprovado, porém, é absolutamente permissivo, minando a geração de interesse para a iniciativa privada em investir em mais potencial construtivo. Em troca de e-mails entre representantes do Conselho da Cidade datada de outubro de 2018, este fato é apontado frisando também a falta de 


\section{SÃOPAULO15 $\quad 17 \cdot$ LISBOA $25 \sim 26$ JUN 2020}

capacidade de suporte de equipamentos e infraestrutura, conjuntamente com o caso do Saco dos Limões: o zoneamento regularmente aprovado deveria ser utilizado somente se promovido em associação a um programa de melhorias infraestruturais da OUC prevista para o local, mas que se mantinha vigente em um prenúncio de completa saturação da região. Hoje, graças ao trabalho do Conselho da Cidade, instância participativa criada após a aprovação do Plano e que, entre outras atividades, discute e constitui emendas para reparação às inconsistências do PD aprovado, foi adicionada uma trava ao texto da lei, condicionando a liberação do potencial construtivo à implantação de uma OUC.

O impasse relacionado à transposição entre OUCs e AUEs também sofre modificações na Câmara. Apesar de elencados no texto da lei, os três casos remanescentes desaparecem do mapa, e as OUCs de Canasvieiras, Ribeirão da llha e Ratones ficam sem perímetro definido, obscurecendo ainda mais o instrumento, suas perspectivas para o município e para com o interesse público.

Em abril do primeiro ano de gestão do prefeito Gean Loureiro, foi proposta a PLC 1632/2017, que "dispõe sobre as áreas prioritariamente destinadas a operações urbanas consorciadas no município de Florianópolis e acrescenta área para realização prioritária de operação urbana consorciada". Dois novos perímetros de OUC tentaram aprovação, mas de forma improcedente: uma OUC, para ser efetivada, deve constar previamente em seu PD aprovado, de acordo com o Estatuto da Cidade. Além disso, a tentativa de implementação dessas duas OUCs ocorreu de forma paralela ao processo de revisão do PD previamente citado, que era promovido pelo poder público municipal nos momentos desse decreto. A gestão municipal seguinte àquela da aprovação do PDMF também demonstrou, assim, não estar realmente comprometida com o interesse público e suas instâncias participativas, ou até mesmo com o planejamento da cidade.

\section{Conclusões}

Neste artigo, observou-se a ubiquidade neoliberal pairando por sobre todos os procedimentos de realização do Plano Diretor. O papel ativo do Estado na transferência da gestão urbana e esquiva dos princípios democratizantes do processo, principalmente em momentos chave de finalização e aprovação. A prefeitura capturou a governança urbana e foi determinante para afastar o PD das demandas populares $e$ desestabilizar o diálogo entre o corpo técnico, a gestão municipal e a sociedade civil durante o processo.

A Câmara de Vereadores, se comportando como uma instância independente de negociação, aprofundou a criação de um plano sem coesão suficiente e sem vislumbre de um projeto de futuro claro, com instrumentos urbanísticos decididos sem estudos suficientes e associados a oportunidades de mercado em detrimento da promoção do interesse público. O resultado observado, no caso das Operações Urbanas Consorciadas, foi a inviabilização do instrumento urbanístico dentro das normativas vigentes.

A abordagem despreocupada de uma lógica de abertura ampla de oportunidades para o crescimento do mercado imobiliário mina as oportunidades de reconfiguração ou expansão urbana dentro da ilha, em direção a uma cidade mais eficiente e saudável. Não dispondo de instrumentos vantajosos o suficiente para direcionar a indústria da construção, Florianópolis nulificará boa parte de seu esforço de planejamento urbano, deixando de atacar seus problemas de infraestrutura, serviços e mobilidade. 


\section{SÃOPAULO $15 \sim 17 \cdot$ LISBOA $25 \sim 26$ JUN 2020}

\section{Bibliografia}

ÁVILA, E. D.; DIAS, V. L. N. (2013a). A iminente e preocupante instalação das operações urbanas consorciadas em Florianópolis/SC. Caminhos da geografia - revista online. V.14. n. 46. Junho de 2013. (2013b). Operações urbanas consorciadas em Florianópolis - SC / Evelyne Delgado Ávila; orientadora: Vera Lúcia Nehls Dias, Florianópolis, SC - 2013, 172 p.

BRASIL. (1988). Constituição da República Federativa do Brasil de 1988. Presidência da República, Casa Civil, Subchefia para Assuntos Jurídicos, 1988. - (2001). Lei oㅜ 10.257 de 10 de julho de 2001. Estatuto da Cidade e Legislação Correlata. - 2. Ed., atual. - Brasília : Senado Federal, Subsecretaria de Edições Técnicas, 2002.

DARDOT, P. (2016). A Nova Razão do Mundo: Ensaio sobre a Sociedade Neoliberal / Pierre Dardot ; Christian Laval ; tradução Mariana Echalar. -1. Ed. - São Paulo: Boitempo, 2016.

FIX, M. (2009). Uma ponte para a especulação - ou a arte da renda na montagem de uma "cidade global". Caderno CRH, Salvador, v. 22, n. 55, p.41-64, jan/abr 2009

FLORIANÓPOLIS (2010), Anteprojeto de Lei Plano Diretor Desenvolvimento Sustentável de Florianópolis, de 16/03/2010. - (2012), Anteprojeto do Plano Diretor de Florianópolis, de 11 de abril de 2012. - (2013), Mensagem 073/2013, PLC n﹎﹎, de 18 de outubro de 2013. _ (2014), Lei complementar ํㅜ 482, de 17 de janeiro de 2014.

GONÇALVES, A. L. S; CHAVES, L. S; SIQUEIRA, M. T (2017). O vai e vem do planejamento urbano: o processo de revisão do Plano Diretor em Florianópolis e a participação popular. IX congresso brasileiro de direito urbanístico.

HARVEY, D. (2005) A Produção Capitalista do Espaço. / David Harvey. - São Paulo: Annablume. (1982) O trabalho, o capital e o conflito de classes em torno do ambiente construído nas sociedades capitalistas avançadas. In. Espaço e Debates, n.6, p. 06-35, 1982.

HARVEY, D. (2008) O direito à cidade. trad. Revista Piauí. New Left Review, n. 53, set./out.

IBGE. (2018). Diretoria de Pesquisas, Coordenação de População e Indicadores Sociais, Estimativas da população residente com data de referência 10 de julho de 2018. (2010). Censo Demográfico 2010.

KRONENBERGER, B.C.; SABOYA, R. T. (2019). Entre a servidão e a beira-mar: um estudo configuracional da segregação socioespacial na Área Conurbada de Florianópolis (ACF), Brasil. Urbe. Revista Brasileira de Gestão Urbana, 11.

MARICATO, E., FERREIRA, J. S. W. (2002) Operação Urbana Consorciada: diversificação urbanística participativa ou aprofundamento da desigualdade? In: Estatuto da Cidade e Reforma Urbana: novas perspectivas para as cidades brasileiras, OSÓRIO, Letícia Marques (org.), Porto Alegre/São Paulo. Disponível em: <http://labhab.fau.usp.br/biblioteca/textos/ferreira_operacoesurbanasconsorc.pdf> acesso em $14 / 04 / 2018$

MISOCZKY, M. C., ABDALA, P. R. Z., DAMBORIARENA, L. (2017). A trajetória ininterrupta da reforma do aparelho de Estado no Brasil: Continuidades nos marcos do neoliberalismo e do gerencialismo. Revista Administração Pública e Gestão Social, n.9(3), p. 184-193, jul/set 2017. 


\section{SÃO PAULO15 17 LISBOA $25 \sim 26$ JUN 2020}

ROCHA, D. L. O Direito à Cidade e a Organização Social em tonro do Plano Diretor de Florianópolis. / Danuza Labanca Rocha; orientadora, Vânia Maria Manfroi - Florianópolis, SC, 2015.

SAMPAIO, J. B. (2016) Florianópolis no processo de elaboração de seu plano diretor participativo, entre 2006 e 2014: um território em disputa / Juliana Búrigo Sampaio ; orientador, Elson Manoel Pereira - Florianópolis, SC.

SIQUEIRA, M. T. (2017). Captura de mais valia do solo e reforma urbana: o caso da Operação Urbana Consorciada Água Espraiada. Tercer Congreso Iberoamericano de Suelo Urbano. - LOPES, A. F. P.; BURATTO, J. H. (2019a). Grandes projetos urbanos à procura de um plano de cidade: contradições e fragilidades na elaboração de operações urbanas consorciadas em Florianópolis, SC. XVII ENANPUR, Natal.

SCHLEDER, C. S. L.; MAGNANTI, I. - (2019b), Áreas de Urbanização Especial: As possibilidades e os entraves na implementação de novos instrumentos de planejamento urbano em Florianópolis, SC. XVII ENANPUR, Natal.

SUGAI, M. I., (2002) Segregação silenciosa: investimentos públicos e distribuição sócio-espacial na área conurbada de Florianópolis / Maria Inês Sugai : orientador Flávio José Magalhães Villaça - Universidade de São Paulo, São Paulo, SP.

VILLAÇA, F. J. M. (1985) A terra como capital (ou a terra-localização). Revista Espaço \& Debates, Ano V, no $16,5-13$. 